\title{
The Combination of Professional Education and Humanistic Education in the Environmental Science Teaching
}

\author{
Jian-qiu CHEN, Rui-xin GUO* \\ Department of Environmental Science, China Pharmaceutical University, 210009 \\ Nanjing, China \\ *ruixinguocpu@163.com
}

\begin{abstract}
Keywords: Teaching Reform; Experiential Teaching; Combination of Professional Education and Humanistic Education; Environmental Science Teaching

Abstract.Taking Environmental microbiology as an example. Carry out reform and exploration of theory teaching content by analyzing the nature of experiential teaching philosophy, combining with personality traits of contemporary college students. It can achieve obvious effect of teaching and also has a good reference for reform and innovation of other pharmacy environmental science courses teaching, by combining professional education and humanities education, motivating students self-consciousness, and cultivating the students' initiative, enthusiasm and consciousness in learning.
\end{abstract}

\section{Introduction}

With the development of the reform of higher education, the problems gradually revealed. Lack of humanistic spirit of contemporary college students, especially in science and engineering college students, mainly displays in the absence of molding humanistic spirit and consciousness. The division of liberal arts and science for a long time and the lack of scientific and technological education of humane connotation result in a universal decline in social values and moral sense [1]. This, together with the current China's social phenomenon of many constitutes the unbalanced development of Chinese economy and culture. The professional teachers are only responsible for professional education, while the humanities education is to establish several public courses of humanity by the department of society science teachers or open some lectures and cultural activities by external experts and scholars. Humanities education is only a supplement to the students after school life and ways for the cultivation of the interest, and the teachers' participation is not enough, especially there is not enough how to integrate the professional teaching to conduct importance and exploration of the humanities education [2].

The current modern higher education of natural science appeared the returning to humanity and humanism, and development trend of the combination of professional education and humanistic education is obvious [1]. Therefore, many universities are beginning to explore the road of humanities education for science and engineering students. Based on science education and let humanities as value orientation have become everyone's consensus. Combining with professional teaching, humanities education has become the main direction of humanistic education in connotative development of colleges [2]. Today, with the rapid development of human society, environmental problems have become a hot issue of contemporary global. Its essence is how to comprehensively understand the relationship between human and nature, how to deal with the problems between humane development and environmental development, and how to define a person's ability, freedom and human value problem. This is an authentic "anthropology" problem, so the environmental science itself has the characteristics of the humanistic spirit and humanistic care [3]. Because only we show the first concerned with "people of learning environment", teach well "people of learning environment", and then realize "people of learning environment" concerning for the environment, finally govern environment well. Hence, environmental science can become typical and representative of the highly combination of professional education and humanities education because of its particularity, and point a new direction and set an example for the higher education development of traditional science. 


\section{Experiential teaching concept in the environmental teaching design-take environmental microbiology course for example}

Modular teaching mode is a set of education system related to the teaching content, which was designed by program modularization idea and principle [4]. It is under the guidance of the established training goal, decomposing all the teaching contents into several relatively independent teaching modules according to certain standards or rules. In classroom teaching, modularization teaching pays attention to the student to actively build the knowledge and skills, promoting the students to acquire knowledge actively in the learning process and apply knowledge to solve the problem. Since environmental microbiology attaches importance to the interrelation between microorganisms and environment, to emphasize the status and role of microorganisms in the environment, course teachers make proper adjustments for the original teaching content in theory teaching link. This part of the original content mainly involves the "environmental microbes". The original content was divided by different environmental conditions, including the microorganisms in the natural habitat and extreme habitat, respectively. Nonetheless, the teacher found that there are both crossing and logical relationship and parallel in the two parts when preparing the content, not being conducive for students to master knowledge [5].

In class, the teacher guides the students to adjust the original content (in Figure 1). According to the "total- points" structure, it is divided into three modules: Module 1 focuses on the role of microorganisms in the ecosystem and effects on microorganisms by environment conditions (total); Module 2 introduces the case of microorganism in two environment (general habitat and special habitat) (points). Based on a connection in the subsequent teaching content such as the microbial adsorption behavior in the habitat and the formation of biofilm and microbial mechanism of aerobic wastewater treatment, the sixth section is singled out in the textbooks, referring to the relevant content of foreign original teaching materials and combining with some latest research results to form module. Module 3, this paper introduces microbial behavior in the habitat (points). Because only have carding and optimization of logical structure on the original teaching materials, it does not involve a major change in content and students do not need to change the teaching material, maintaining the continuity of the teaching. What's more important is that teachers lead students to participate in and complete together in the whole adjustment process, making a full explanation and illustration for the students with every step changes. Students in such a process not only know how to adjust, but understand the "why adjust", see the problem with critical thinking and dialectical attitude, break the unscientific understanding of "holy" textbook and truly understand the "believe books entirely may as well not read". The real purpose of teaching is to help students to experience what are learning process and the method of how to learn. Only in this way is it the true quality education.

The theory basis of experiential teaching is constructivism. Constructivism considers that learning should be an active constructional process, emphasizing students-centered, the student being the subject of cognition, while the teacher only help and promote the students' sense-making [6]. Hence, contain situation creation and collaborative learning in the teaching, and on this basis the learners themselves eventually realize the meaning construction for knowledge. In the field of education, there are such that "speak once is better than read three times". The meaning is that it is not enough to understand knowledge only by "look inside" (input), and it is the true master only through "tell" after their own processing (output). It raised the teacher thinking: can we set such situation in teaching that let students experience the teacher's role, the students teach knowledge for students, center "experience growth" of the students, power the potential of students, and combine learning and the students' interest and desire. So in environmental microbiology experiential teaching mode, teachers create a number of participatory teaching scene purposively and consciously, guide students to gain knowledge and comprehension and enhance ability though the experience activity by themselves. This is a teaching process which dominated by teachers, students as the leading role to complete the principal transformation. The teaching mode embodied in: "import - experience - share - summary". In the first stage of "import", teacher start with teaching aims and students' knowledge level, combining with the former content to construct the chapter before the experience. According to the 
former modular teaching mode, the related contents in the this part are combed into a number of modules such as "microbial related to animals and plants", "microorganisms and human" and " microbes and element circulation "and "microbial and environmental pollution" and so on. We have made the detailed rules for simulation teaching experience. The students play the leading role of "experience". At this stage, firstly students completed the preparation before class in the form of group, and then combined with ample multimedia resources to carry out the "teaching" in the way of one people, two people or more people speaking. The students' learning effects are greatly improved because of this new form and closer language to the students. In the "Share" stage, the students start self-knowledge after hand on and know each other. The teacher asked the students to summarize the knowledge of the key and difficult point with the role of "teacher", and look up related literature combining with the learned information in the literature and information retrieval lesson. As "the host" of this stage, the teacher encourages and guides students to reflect and express their true feelings after the teaching experience, especially requiring them to dig the real cognition and discuss, share, exchange and learn from each other on the basis of self-reflection. For instance, a student found that the research of the relationship between drug and microorganisms is relatively insufficient after making literature reports about microbial dependence on metal and the toxic effect of metal to the microorganisms, then proposed to the teacher with other students whether conduct the related experiment in the laboratory. Therefore, experience is not a purpose, but a mean. We can review, explore, conclude, confirm on the basis of experience and eventually improve cognition. This professional teachers accordingly establish some extended projects such as "behavior research of biology degrading drug in lake sediment environment”, "research environment effect of antibiotics on microalgae" and so on combining with research projects, to encourage the students to participate in scientific research project after class. It not only takes the initiative to establish a link between knowledge learning and application, and well received by the students, but also embodies the pharmacy characteristics of our school. Many students even hope that can be their open project and graduation thesis topic, continuing to research after the environmental microbiology course. "Summary" stage is the enhancement of the whole course and is also a prerequisite to success experiential teaching. Teachers lead the students to summary and comment on the teaching content on the basis of the reflective discussion, activate invisible education factors implicating in the teaching, arouse self-consciousness of students, help students to change their cognition in experience, and format motivation to change their own. Then utilize these feelings and changes in the real environment and bring the transition of the individual learning ability and promotion of comprehensive quality.

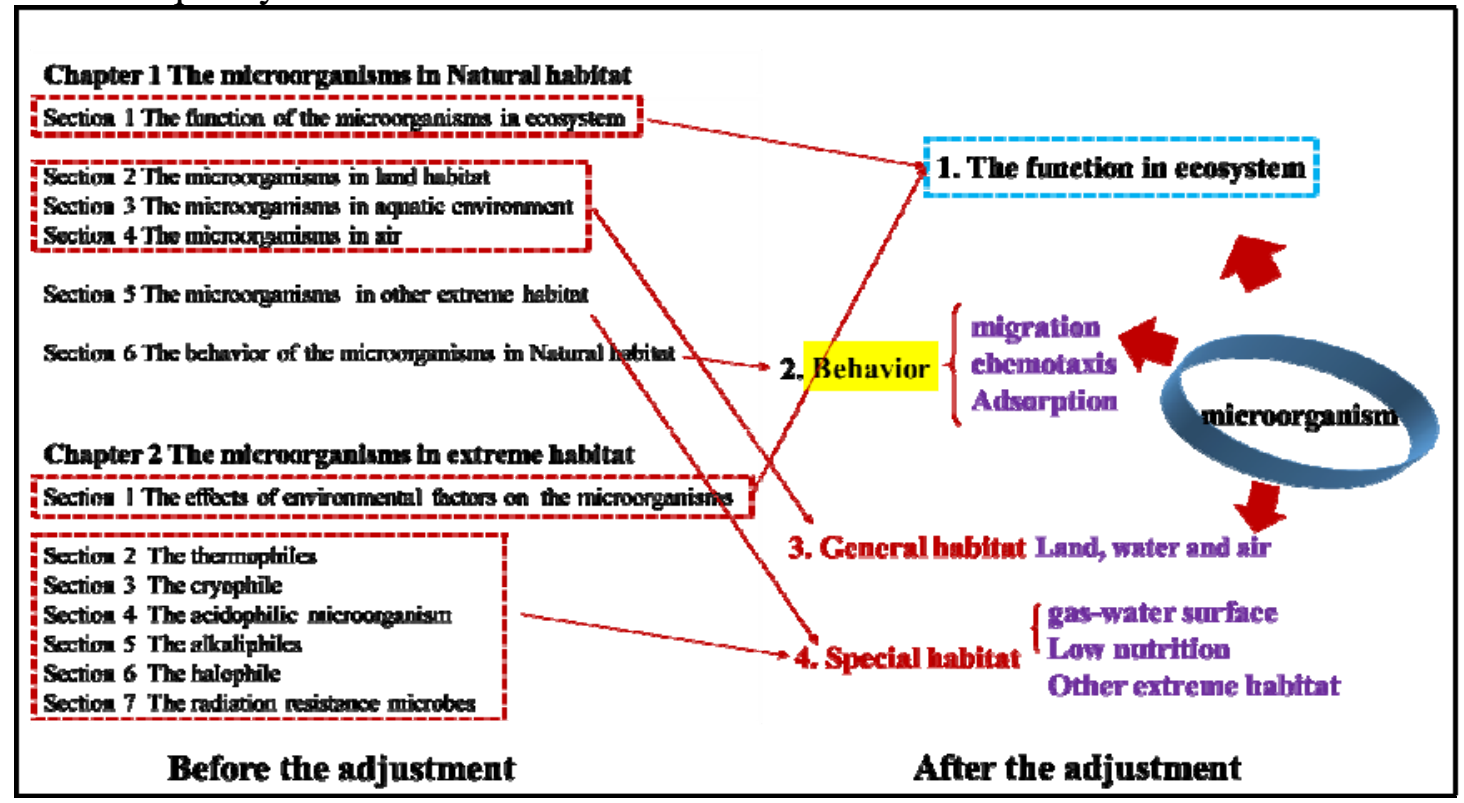

Figure 1 The adjustment of the original contents 


\section{Summary}

Therefore, the implementation of the teaching process should pay attention to the development of students' "self-consciousness". The teachers only play a guiding role, not scripted, not directly tell students how to do it and what the results should be obtained. To get rid of the shackles of the "didactic" teaching, fully respect the discipline and personality characteristics of the students growth, meet the demands of the students' cognitive, and inspire the students initiative, enthusiasm and consciousness in learning, achieve learning goals in a pleasant situation, these make the whole teaching process as "spring rain moisten everything silently".

\section{Acknowledgement}

This work was supported by The natural science foundation of Jiangsu Province Youth Fund (BK20130646, BK20140653/SBK2014041047), Jiangsu Key Lab of Environmental Engineering Open Foundation (KF2012008), Doctor Scientific Research Foundation from China Pharmaceutical University (2012ZJ13002), National Undergraduate Training Programs for Innovation and Entrepreneurship (02640556, G14005), the Fundamental Research Funds for the Central Universities (JKQZ2013009, JKPZ2013017) and Qing Lan project (2014).

\section{References}

[1] X.J. Liu: Journal of Higher Education. 23 (2002) 1-6.

[2] L.Y. Zhang, R.Tao: Journal of Zhaotong Teacher’s College. 26 (2004) 58-62.

[3] L. Zheng: Education Exploration. 8 (2008):125-126.

[4] Y.H. Zhao, F. Wu, L. Liu, X.L. Dong, L.L. Dong: Tribune of Ideological and Theoretical Education. 1 (2010) 108-112.

[5] P. Guo, H.P. Zheng: Chinese Adult Education. 14 (2009) 53-54.

[6] J. Guo, G.X. Li.: Journal of Bejing Jiaotong university (the social sciences) 1 (2010) 124-128. 